REVISTA NOMADÍAS

Julio 2011, Número 13, 103 -128

\title{
Derrotando el bigenerismo*: cambiando supuestos de género en el siglo XXI
}

\author{
Miqqui Alicia Gilbert \\ York University. Toronto, Canadá. \\ Gilbert@YorkU.ca \\ Traducción: Inger Flem \\ Universidad de Chile \\ inger.flem@gmail.com
}

El Bigenerismo (binarismo de género) plantea que sólo hay dos géneros, los cuales corresponden a dos sexos, masculino y femenino. El bigenerismo básico requiere que documentos legales e instituciones públicas designen un solo género invariable (esto es, el sexo). El bigenerismo estricto aplica estas categorias en un contexto social que estigmatiza como "imperfecto" a hombres y mujeres que no alcanzan los ideales impuestos por el esquema bigenerista. Discuto estos conceptos y sus implicancias, presento tres modelos que sucesivamente debilitan los supuestos bigeneristas, y abogo por el más radical de los tres.

Toda interacción que tenemos con otros seres humanos está fundamentada en las categorías en las que espontáneamente las posicionamos, incluyendo incluso el color de piel, etnia, edad y clase. Mientras estas importantes categorías pueden estar individualmente indeterminados, toda interacción es enmarcada por la relación de género entre nosotros; por lo tanto, colocarnos en la categoría sexual de femenino o masculino es esencial. No tener información de la categoría sexual puede significar que somos prácticamente incapaces de interactuar e imposibilitados de comunicar. Como resultado, la necesidad de clasificar por sexo es abrumante, y la confusión o vacilación es una gran causa de incomodidad y, algunas veces, de rabia. Esta reacción es una función de lo que llamo el sistema bigenérico. En lo siguiente, presento 
el sistema bigenérico, su naturaleza, y defectos. Luego describo tres sistemas de sexo/género que progresivamente se alejan del punto de vista prevaleciente y estrictamente dicotómico. Finalmente, abogaré por el más radical de los tres, el no-generismo, en el que el género desaparece. Argumento que este es el sistema ideal, en tanto que elimina el sexismo, heterosexismo, homofobia y transfobia.

Judith Butler afirma que no es posible ser simplemente o meramente una persona; uno debe ser una persona masculina o una persona femenina, un hombre o una mujer. Ella escribe: "las personas sólo se vuelven inteligibles tras ser generizados en conformidad a estándares reconocibles de inteligibilidad de género" (Butler, 1990, 122). Para llegar a ser una persona inteligible, uno debe manifestarse dentro de las bien conocidas y bien establecidas reglas del género. Estas reglas nos instruyen en cómo comportarnos, incluyendo el cómo caminar, hablar, y relatar a otros del mismo género, y también del género opuesto. Ellos delinean qué carreras y pasatiempos son correctos, qué intereses románticos son apropiados, qué temores, ambiciones, y expectativas uno debería tener. Estas reglas determinan quién puede reír, quién puede llorar, quién peleará, quién debería jugar con autos y quién con muñecas. Estas reglas detallan quién abre puertas y retira sillas, el lado de la vereda en que uno camina, y cómo, y si es que, puede hacerse contacto visual. Hay especificaciones sobre expectativas de ganancias, responsabilidad financiera, responsabilidad familiar, y las consecuencias del flirteo sexual. Las reglas del género cubren todo lo que hacemos y decimos, y lo hacen sin parecer en absoluto que estamos siendo coaccionados o siquiera tomando decisiones.

Estas reglas, que han evolucionado a través de varias generaciones, son exactamente aquellas reglas que protegen el marco patriarcal a través del cual mujeres y minorías sexuales y de género han sido oprimidas y controladas. No obstante, para la mayoría de las personas, estas reglas y requerimientos aparecen sin mayor relevancia y no presentan dificultades o retos. Por una parte, están naturalizadas a través de infinitas repeticiones que son ambas vigentes e históricas (Goffman, 1977; Kessler and McKenna, 1985). West and Zimmerman lo explican como a continuación:

Hacer género también hace que se pueda dar cuenta de los arreglos sociales como normales y naturales, o sea, modos legítimos de organizar la vida social. Las diferencias entre hom- 
bre y mujer, que son creadas mediante este proceso, pueden ser "retratadas" como disposiciones fundamentales y duraderas. Bajo esta luz, los arreglos institucionales de la sociedad pueden ser vistos como una respuesta a las diferencias, donde el orden social es meramente un acomodamiento al orden natural. (West and Zimmerman, 1987, 146)

Lo "natural" de las reglas del género es el fundamento de que sean incuestionados y el motivo de por qué un objetivo histórico central del feminismo ha sido exponerlos a ellos y su naturaleza sexista como arbitrarios y contingentes. El apuntalarlos es también una ideología naturalizada del sistema de género dicotómico. La asumida naturalidad del sistema de género significa que cualquiera que lo viola está siendo "antinatural" y es, por lo tanto, merecedor de censura. Obviamente también, los transgenerizados, en particular, están en directa violación de estas reglas y no deberían ser permitidos prosperar, si es que, claro, están permitidos existir.

Mientras las reglas del género son infinitamente sutiles y variables, las reglas aceptadas por la mayoría de las personas son básicas y fácilmente identificables. Bornstein (1994), adaptando de Garfinkel (1967), cita estas reglas como generalmente aceptadas por la población en general:

Las Reglas del Género

1. Existen dos, y sólo dos, géneros.

2. El género de uno es invariable.

3. Los genitales son los signos esenciales del género.

4. Cualquier excepción no es seria.

5. No hay transferencias de un género a otro (sin ceremonia).

6. Todos son de un género u otro.

7. La dicotomía Masculino/Femenino es de carácter "natural".

8. La afiliación a un género u otro es "natural".

Claramente, de acuerdo a las reglas no existe alguien cuyo sexo o género diverja de su sexo designado por nacimiento, lo que significa que la gente trans no puede existir. Sin embargo, un corolario dice que si alguien llegara a cambiar su sexo debe ser de uno de los dos sexos al otro. La única cosa que está absolutamente prohibida es un género que no caiga ordenadamente en una de las dos categorías.

A la luz de estas reglas, quiero definir el "bigenerismo" 
como un punto de vista que acepta las reglas del género y que no permite variaciones, excepciones y / o desviaciones de la regla (Gilbert, 2003). El principal empuje de las reglas es establecer que hay dos, y sólo dos, géneros, y que todos deben ser uno u el otro. Este nivel de bigenerismo es su forma básica, y no sólo un hecho de percepción popular, sino ampliamente oficial también. Lo que podríamos llamar "bigenerismo básico" es encontrado en todos los dispositivos burocráticos e instituciones que gobiernan nuestras vidas a diario. Gobiernos, colegios, hospitales, las profesiones, las artes y virtualmente todas las instituciones sociales dependen del bigenerismo básico como una forma de clasificar y categorizar a aquellos que se aprovechan o que entran en contacto con sus servicios o necesidades. El bigenerismo básico es presenciado en la plétora de formas burocráticas que tienen dos cajas o espacios ofreciendo la opción de masculino o femenino para el sexo y/o género, con alguna que otra excepción. Por supuesto, las ocurrencias más penetrantes e insistentes de la bifurcación del género ocurren en las interacciones entre individuos y baños públicos. Cuando se va al baño en un escenario institucional, uno debe tomar la decisión pública entre una de las dos opciones, y tomar una decisión inadecuada puede causar cualquier cosa, desde hilaridad hasta profunda rabia y violencia. La separación de baños, o como lo llama Goffman (1977) "segregación de baños", Bornstein (1994, citando a Lacan) "segregación urinaria" y Halberstam $(1998,20-29)$ "problema del baño", es una manera penetrante de etiquetar y marcar a los individuos de acuerdo al sexo. ${ }^{1}$ Es más, como lo explicaré después, la separación de baños juega un rol aún más profundo e insidioso en el mantenimiento del bigenerismo.

El bigenerismo básico obviamente tiene un mayor impacto en aquellos miembros de la sociedad que se identifican como genéricamente diversos. Transexuales, intersexuados, travestis, "queers" de género y andróginos todos deben seguir las reglas y procedimientos dispuestos para lo que Garfinkel llama los "normales". Ya que toda la gente de diversidad de género debe constantemente escoger un baño, ir marcando en una casilla $\mathrm{M} / \mathrm{F}$, e ingresar a uno de los dos posibles camarines, no hay oportunidad para ser cualquier cosa menos uno o el otro. Uno debe "pasar" o sufrir las consecuencias de la censura social. Esto tiene implicancias para tales consideraciones, como tener una cirugía genital y de otros tipos, encontrando y manteniendo empleo y vivienda, tanto como la habilidad de estar involucrado en relaciones amorosas. 
Para poder entender apropiadamente el bigenerismo, será de ayuda el conceptualizar la misma interactiva estructura sexo/ género. Para ayudar en esto usaré la terminología de West y Zimmerman. Ellos usan tres términos básicos de los cuales uno puede desarrollar otros:

El sexo es una determinación hecha a través de la aplicación socialmente aceptada sobre información biológica para la clasificación de personas como hembras o machos (categoría sexual) [...] es establecido y sostenido por las manifestaciones de identificación socialmente requeridas que proclaman que la afiliación de uno es a una u otra categoría [...] La categoría sexual presume el sexo de uno y se levanta como su representante en muchas situaciones, pero el sexo y la categoría sexual pueden variar independientemente [...]

Género [...] es la actividad de manejar conducta situada a la luz de concepciones normativas de actitudes y actividades apropiadas para la categoría sexual de uno (West y Zimmerman, 1987, 127)

De este modo, el sexo es una clasificación biológica y típicamente legal que, interesantemente, no juega una mayor función social en un modo diario. No malentienda: el sexo es en sí mismo quizás el hecho de identificación más importante de alguien, y el establecimiento del sexo designado por nacimiento de uno crea expectativas, límites, y roles que acompañan a uno a través de la vida. Sin embargo, el usar varios medios de alteración, y al violar las expectativas de presentación que el sexo designado por nacimiento delimita, uno puede aspirar a ser colocado en una categoría sexual que no es, de hecho, el sexo designado por nacimiento de uno. Un hecho simple de la vida social que Kessler y McKenna famosamente señalan es que aunque queremos hacer que los genitales sean la base del sexo, es sólo rara vez que estamos en una posición de ver los genitales del uno al otro (Kessler y McKenna, 1985). Es aún más raro que tal visión involucre una inspección lo suficientemente cerca como para detectar manufactura o artificio. El resultado es que la mayoría del tiempo estamos realmente tratando con la categoría sexual más que con el sexo; esto es, ya que no conocemos realmente la situación genital de cualquier individuo dado, hacemos suposiciones y sacamos conclusiones acerca del sexo basados en la manifestación del género.

El ser capaz de adoptar una particular manifestación del 
género y la concomitante invisibilidad pública de los genitales es donde se crea el espacio para los transexuales y los travestis. Uno es capaz hasta tal punto, al manifestar indicadores de género de su género escogido, que uno trata de ser clasificado en la categoría sexual de su elección independientemente del sexo realmente asignado inicialmente. En la medida en que la categoría sexual es adjudicado por uno de esos encuentros, la colocación en una categoría sexual se vuelve un logro individual. En efecto, el logro de categoría sexual es aplicable a todos los miembros de la sociedad: los "cisgenerizados" (esto es, aquellos que viven cómodamente en su género designado por nacimiento) o los diversos de género. A menudo en una clase universitaria de ciento cincuenta alumnos he señalado que ni uno de ellos falla en manifestar marcas de género definitivos y no ambiguos, ya sea el peinado, vello facial, vestimenta, joyería, maquillaje, u otro indicador de género no ambiguo. Ciertamente, hay personas que escogen desafiar o eludir las reglas de género, pero ellos forman una minoría y a menudo reciben una desaprobación considerable, que incluso llega hasta la muerte. ${ }^{2}$ El bigenerismo dicta que hay sólo dos categorías -femenino y masculino- y esto significa que todos deben no sólo estar en una de esas categorías, sino que todos deben también ser colocados en una de aquellas. Ridgeway y Correl lo plantean así:

Si las creencias culturales sobre el género son las reglas para representar el sistema de género, los contextos sociales relacionales son las arenas en donde estas reglas son aplicadas sobre el comportamiento y evaluaciones de los individuos. El proceso que conecta las creencias de género y contextos sociales relacionales es una categoría sexual automática. La categorización sexual es el proceso sociocognitivo por el cual etiquetamos a otro como macho o hembra. Como categorizamos sexualmente al otro, por implicancia, nos categorizamos sexualmente a nosotros mismos como similares o diferentes a ese otro. (Ridgeway y Correll, 2004, 514)

Hasta el momento he estado discutiendo acerca de lo que he venido llamado bigenerismo básico. Eso, sin embargo, es sólo la punta del iceberg. De hecho, el bigenerismo es una división sistemática de la población no sólo por el sexo, sino también por un sistema extraordinariamente complejo, sutil y refinado de comportamiento, ademanes, comunicación, presentación e interacción. Este nivel de bigenerismo, lo que podríamos llamar "bigenerismo sistémico", permea cada aspecto de nuestras vidas 
y controla y dicta cada movimiento, palabra y pensamiento. Es el bigenerismo sistémico lo que afecta a cada individuo y causa estrés y ansiedad para una multitud que no se consideraría a sí misma como diversa de género.

El bigenerismo, además, es también una piedra angular de la heteronormatividad, en la medida que conlleva la implicancia de que dos géneros pretenden emparejarse heterosexualmente. En efecto, el bigenerismo y la heteronormatividad son simbióticos: la heterosexualidad depende del supuesto de que los genitales de un individuo van en concordancia con la apariencia de su género, y el bigenerismo asegura que las categorías sean demostrativas.

De la mano con el bigenerismo y la heteronormatividad, y con lo que últimamente impulsa a esto como una problemática feminista, es la infusión del sexismo desenfrenado a ambos de estos conceptos. El bigenerismo y la heteronormatividad aseguran que el mundo esté dividido en Mujer y Hombre, y el sexismo se ocupa de que la Mujer sea subvalorada y el Hombre sobrevalorado. Eliminar las categorías mismas es una manera de eliminar el sexismo que depende de ellas. Pueden haber otras maneras de alcanzar ideales feministas, pero el destierro del bigenerismo y de la heteronormatividad también elimina la homofobia y transfobia. Esto es porque la adjudicación externa de la localización de un individuo en un micro mundo de sexo/género bigenérico significa que el status procreativo y la elección de pareja de uno están determinados simultáneamente por esa localización.

La importancia del proceso de adjudicación puede ser clarificado usando los términos de West y Zimmerman introducidos arriba. La Tabla 1 clarifica la dinámica.

Note que los adjudicadores en las tres divisiones categóricas son observadores externos, y, exceptuando las circunstancias comparativamente poco comunes de los nacimientos intersexuales, todas las categorizaciones son asumidas como definitivas y permanentes. Incluso en el caso del intersexo, es sólo el sexo y no la categoría sexual o género lo que está, luego de periodo inicial de confusión, en cuestión.

La tiranía del bigenerismo sistémico se muestra en la terminología aplicada a aquellos que no cumplen con las clásicas expectativas de género. Éstos son los mariquitas (sissies), marimachos (tomboys), y más recientemente los niños y hombres afeminados (girlie boys and men). Además, cualquier signo de lo femenino en un hombre o de lo masculino en una mujer lleva a acusaciones y / o suposiciones de homosexualidad. A sí mismo, 
las reglas y regulaciones del bigenerismo sistémico son extraordinariamente extensas y estrictas. Muchos (de una cierta edad) recordarán la instrucción de trampa, "Oye, mira tus uñas". Si estirabas la mano, con la palma mirando hacia abajo y los dedos hacia adelante, eras etiquetado como niña. Si estirabas la mano, con la palma mirando hacia arriba y los dedos semi-empuñados, eras etiquetado como niño. El bigenerismo sistémico delinea los tipos de comportamientos que son aceptables e inaceptables para cada uno de los dos géneros. Por implicancia esto lleva a una jerarquía de la masculinidad y feminidad donde los individuos son evaluados dependiendo de qué tan bien (o no) se comparan a los ideales de la ideología bigenerista. En este sentido, el bigenerismo es una trampa: primero declara que uno debe pertenecer a uno de los dos géneros, y luego juzga a la gran mayoría que no está a la altura de los estándares del género al cual fueron asignados.

Tabla 1

Clasificaciones hechas por otros

\begin{tabular}{|c|c|c|}
\hline \multicolumn{1}{|c|}{ Término } & \multicolumn{2}{c|}{ División } \\
\hline Sexo & $\begin{array}{c}\text { Femenino (hembra)- } \\
\text { Masculino (macho) }\end{array}$ & Médico/Legal \\
\hline Categoría Sexual & Mujer-Hombre & Otros \\
\hline Género & Femenino-Masculino & Otros \\
\hline
\end{tabular}

Los géneros son gobernados por varios criterios que, mientras pueden hacer y hacen oscilaciones de acuerdo a la edad y subgrupo, aún tienen características abarcadoras que son rígidamente aplicadas dentro de la sociedad en general. Cada género tiene su jerarquía y estándares. El mito de la belleza femenina, por supuesto, ha sido examinado y es conocido como una conglomeración de estándares patriarcalmente determinadas de atractividad, personalidad, habilidad y sexualidad, que induce a estrés, de manera casi Sisífea. Las niñas de "primera categoría" que parecen tenerlo todo son sin embargo plagadas de inseguridades y carentes de confianza en sí mismas porque dependen de aprobación masculina para su estatus. Pero aún están lejos de aquellos cuya suerte en el juego, creado por estándares heterosexistas y sexistas, los hizo "inatractivos". El mito de la belleza masculina requiere fortaleza, ser guapo, y un logrado grado de atletismo. Los ganadores de la lotería de la genética que anotan 
alto en todas estas categorías se vuelven niños de "primera categoría" que parecen ser los mejores en todo, se vuelven los jóvenes más "bacanes" (coolest) de la secundaria, y se deleitan con su popularidad y prestigio. ${ }^{3}$

Sería difícil quejarse si el asunto principal fuese que algunos estudiantes de secundaria tienen suerte y destacan, así recibiendo más bienes que el resto de nosotros; tales quejas pueden ser consideradas nada menos que uvas ácidas. No, la dificultad no concierne a aquellos que les va bien, sino a aquellos que no. La niña que no es "atractiva", que se desarrolla tarde, que tiene un sentido pobre de equilibrio y desenvoltura quedará fuera del círculo íntimo, y su autoestima e imagen de sí misma probablemente serán formados por aquellos que la juzgan pobremente. El niño que es delicado, o aquellos cuya coordinación ojo-mano es espantosa, o quien es pequeño, torpe, o que se ve "extraño", o quien simplemente no encaja se transforma en blanco de matonaje, irrisión, ostracismo, o, por lo menos, expulsión a un grupo de jóvenes similarmente designados, por ejemplo, los "nerds".

El bigenerismo dice que hay maneras específicas de ser mujer y maneras específicas de ser hombre. Si te escapas de esos parámetros, entonces eres justamente eso, un forastero. Sí, a medida de que envejecemos puede ser que encuentres tu camino, y los valores pueden cambiar, pero ese camino temprano, sin importar el éxito alcanzado más tarde en la vida, será siempre el camino por el que estuviste obligado a caminar. Y, como un moretón reciente, basta con un toque en el lugar equivocado para hacer surgir dolores e incomodidad. La rigidez de las categorías y los estándares dentro de ellos significan que es extremadamente difícil para alguien que no es híper-femenino o híper-masculino recibir una alta evaluación.

Mientras que gran parte de la población a la larga sufre bajo el bigenerismo, las personas trans y de género diverso seguramente sufren muchísimo. El problema es que no hay espacio en el mundo del bigenerismo para auto-identificación o clasificación. La Tabla 1 anterior demuestra que el sexo y el género están engranados para ser identificados, clasificados y categorizados por otros a pesar de las categorías que uno quiere. Así, hay una necesidad de categorías de auto-clasificación respetadas y aceptadas; el supuesto de la categoría sexual necesita ser abandonada. Hay dos términos que describen la auto-adjudicación y que serán útiles aquí. El primero es "Manifestación de Género", que involucra la representación voluntaria del uno mismo en la forma tradicional de presentación de uno de los dos géneros. De 
modo similar, la "Categoría Sexual Escogida" es una decisión tomada por uno mismo para uno mismo como se indica en la Tabla 2 abajo.

La libertad de auto-categorizar vuela directamente a la cara del bigenerismo. En primera instancia, el planteamiento de que la apariencia de género supone el sexo, debe ser abandonado. En segundo lugar, debe ser posible permitir que un individuo escoja un sexo al cual no fue asignado por nacimiento. Esto no es más que la des-genitalización del sexo y del género, tarea que requiere mucho más respeto individual y aceptación que la actualmente disponible. La auto-categorización requiere una organización cultural no-jerárquica que acepte la diferencia y variabilidad sin enjuiciamientos. Las "Reinas del Baile" pueden ser celebradas y continuar desechando pretendientes, pero las niñas simples, los inteligentes y los jugadores de hockey no serían apartados o rechazados. Los niños dorados pueden continuar siendo tan guapos y atléticos como se les sea posible, pero a los "nerds" y "geeks" les estaría permitido prosperar, y los niños afeminados o mariquitas (sissies) no serían molestados. ${ }^{4}$

Cualquiera que ha asistido a la secundaria seguramente reaccionará a todo esto con completa incredulidad. "¡Esto nunca podría suceder! ¡Las "Reinas del Baile" no miran en menos a las niñas simples e inteligentes o a marimachos jugadores de hockey! ¡Los atléticos no molestan a los "nerds" y mariquitas! Nunca sucede." Esta sola incredulidad demuestra lo persuasivo que es el bigenerismo, y lo escandaloso que es la idea de alterarlo, ni hablar de eliminarlo. Mas nos permitimos ser ensillados con un sistema que discrimina entre la mayoría de la población, porque la mayoría de nosotros fallamos en encajar en los estándares extremadamente rígidos que el bigenerismo demanda. Sin embargo, continuamos "haciendo" género en nuestras actividades diarias, detallados como son hasta la minucia más fina. West y Zimmerman escriben: "Hacer género involucra un complejo de actividades perceptivas socialmente guiadas, interaccionales, y micro políticas que arrojan persecuciones particulares como expresiones de "naturalezas" masculinas y femeninas." (West y Zimmerman, 1987, 126). Tampoco son sólo persecuciones: es todo lo que hacemos y cómo lo hacemos. Hacer género refuerza el proceso y le da la chapa de "natural", esto es, que la constante repetición de actividades en forma generizada los hace parecer como si esa fuera la única o la única forma real de hacerlo. Como famosamente dijo Judith Butler, "el género es un tipo de imitación del cual no hay original; es más, es un tipo de imita- 
ción que produce la noción misma del original como un efecto y consecuencia de la imitación misma" (Butler, 1991, 312). Esta instanciación de naturalidad es una razón de por qué el género criminaliza, aquellos que violan reglas del género de maneras sutiles o desorientadoras, en oposición a, digamos, bandidos de género o "queers" de género, aquellos que desafían las reglas del género descarada y escandalosamente, tienen mayor probabilidad de sufrir ataque y separación. Si cada actividad tanto refleja y establece el género, entonces cualquiera que no sigue las reglas de tal actividad está violando y fallando en el mantenimiento de la normalidad del género. Ipso facto uno es anormal.

Tabla 2

Auto-clasificaciones incluidas

\begin{tabular}{|c|c|c|}
\hline Término & División & Adjudicador \\
\hline Sexo & $\begin{array}{c}\text { Femenino (hembra) - } \\
\text { Masculino (macho) }\end{array}$ & Médico/Legal \\
\hline $\begin{array}{l}\text { Categoría } \\
\text { Sexual }\end{array}$ & Mujer-Hombre & Otros \\
\hline Género & Femenino-Masculino & Otros \\
\hline $\begin{array}{l}\text { Manifestación } \\
\text { de Género }\end{array}$ & Femenino-Masculino & Uno mismo \\
\hline $\begin{array}{c}\text { Categoría } \\
\text { Sexual Escogida }\end{array}$ & Mujer-Hombre & Uno mismo \\
\hline
\end{tabular}

Una razón para esto puede ser explicado por Erving Goffman: "Si el género es definido", escribió, "como el correlato culturalmente establecido del sexo (ya sea como consecuencia de la biología o aprendiendo), entonces la manifestación del género se refiere a representaciones convencionalizadas de estos correlatos" (Goffman, 1979, 1). En otras palabras, las Reglas del Género dictan que hay dos y sólo dos géneros, y el presentarse en un género dado significa que tienes el sexo correspondiente. Consecuentemente, si estás presentando una imagen mixta, estás despistando a una potencial pareja sexual con respecto a qué tan apropiado eres. En ciertas jurisdicciones, el descubrir que un individuo que uno pensaba que era, digamos, femenino es en realidad masculino puede ser una excusa legal para rabia sexual conduciendo a la violencia. A pesar de lo horripilante que esto es, podría acerca a explicar el asunto, pero no lo suficiente. No hace 
nada, por ejemplo, el explicar por qué tantos individuos que son obviamente miembros de una categoría sexual dada pero que tienen algunos rasgos del otro género son también acosados, muchas veces hasta el punto de la violencia. En otras palabras, por qué una mujer amachada que claramente no es un hombre, o un hombre afeminado que de ninguna manera parece ser mujer, evocan antagonismos tan vociferantes. El mismo hecho de estas reacciones desmienten la sugerencia de que la raíz causante del bigenerismo es la desinformación procreativa.

La respuesta a esta cuestión central descansa sobre el hecho de que la manifestación de género cubre un gran sentido de autopresentación, y la muñeca "quebrada" o el corte de pelo marimacho presentan un desafío al bigenerismo. La vestimenta, en otras palabras, es sólo uno de los aspectos de nuestra presentación de género, y los modales físicos frecuentemente presentados por un hombre afeminado deben, e hipotetizo aquí, provocar alguna respuesta sexual programada por las reglas del bigenerismo. El punto que trato de demostrar es que las señales que emitimos para los propósitos de atracción de parejas son diversos, complejos, sutiles y frecuentemente no intencionales. Debajo del reino del heterosexismo como regulado por las reglas del bigenerismo, virtualmente todos los movimientos son asignados a uno de los dos géneros. Cuando un individuo ha sido categorizado sexualmente, cualquier indicador perteneciente a sexo "opuesto" enviará una señal de "sexo-equivocado". Estas señales son extraordinariamente diversas y abarcan todo. No es meramente la presentación, evidente o no, de características sexuales secundarias o incluso primarias; incluye la manera en que funcionan nuestros ojos, la manera en que nuestras manos caen, la manera en que nuestros cuerpos se mueven y se paran, y un incontable número de otras señales tanto sutiles como directas. ${ }^{5}$ El bigenerismo plantea que las señales son específicas de los sexos y que pertenecen exclusivamente a un sexo o a otro, y que cruzar esa línea está prohibido. Un hombre que mueve sus caderas de manera femenina o cuyos ojos se comportan de modo femenino está enviando señales sexuales - intencionales o no. Esto nada tiene que ver con ser provocativo; mas que nada concierne a la categorización sexual y sus ambigüedades. ${ }^{6}$

En la categorización sexual ambigüedades pueden ser aceptables, salvo que el macho, recibiendo las señales, esté condicionado por una cultura bigenérica, sexista, y heterosexista a tener una reacción: el reaccionar a tales señales como si estuvieran siendo enviados por una hembra. El problema es que tendrá 
tal reacción en un grado u otro, aunque éste sea involuntario e inconciente. Entonces, si es que hay, como algunos insisten, un instinto de copular primario fuerte, entonces el tener una reacción de excitación puede explicar la fuerza del bigenerismo. Pero, ya que es improbable que la reacción de excitación sea muy fuerte, entonces la construcción social del sexismo, homofobia, y heteronormatividad sobre el que el bigenerismo descansa es más probablemente una explicación. Michael Kimmel propone un complejo de factores que juntos le dan sentido a la masculinidad que provee una base para el bigenerismo (Kimmel, 1994). Kimmel basa su teoría en asuntos de separación Freudianas, la idea de competencia, y el temor a ser femenino. La separación de la madre y la identificación con el padre lleva, en el análisis final, a la fundamentación de la hombría en competencia y agresión. Kimmel escribe:

Esto, entonces, es el gran secreto de la hombría Americana: Le tenemos miedo a otros hombres. La homofobia es un principio de organización central de nuestra definición cultural de la hombría. La homofobia es más que el miedo irracional a hombres homosexuales, más que el miedo a que nos puedan percibir como homosexuales... La homofobia es el miedo a que otros hombres nos desenmascaren, nos emasculen, y nos revelen a nosotros y al mundo de que no estamos a la altura, que no somos realmente hombres. Tenemos miedo de permitir que otros hombres vean nuestro miedo. El miedo nos da vergüenza, porque el reconocimiento de miedo en nosotros mismos es prueba de que no somos tan hombres como pretendemos ser... Tenemos vergüenza de tener miedo. (131)

Si agregamos excitación subliminal a la mezcla de Kimmel se hace más fácil entender el tipo de rabia que los violadores del bigenerismo despiertan. La homofobia, en mi modelo, se transforma en miedo a una reacción involuntaria a una señal de categoría sexual. Mientras el miedo a la emasculación puede venir, en nuestra cultura, de las fuentes que Kimmel cita, la excitación viene del proceso histórico de apareamiento y procreación. Si el análisis causal de Kimmel, esto es, la ansiedad de separación Freudiana, es correcta o no es esencialmente irrelevante. Lo que importa no es por qué la masculinidad es tan frágil, sino simplemente que lo es.

Aunque otros usan distintos caminos causales, Kimmel no se encuentra solo cuando sugiere que la confianza tentativa y agarre efímero que los machos están condicionados para tener acerca de la masculinidad descansan en la base de la homofobia, 
heterosexismo, tanto como mucha violencia hacia las mujeres y a los diversos de género. Patrick Hopkins escribe: "Encuentro que una manera de leer a la homofobia y el heterosexismo en hombres es en términos de la amenaza de la homosexualidad a la masculinidad, que a la luz de la conexión entre el género y la identidad personal se traduce en una amenaza a lo que constituye al sentido de sí mismo de un hombre" (Hopkins, 1998, 170). Para Hopkins la explicación involucra la separación de la madre, lo que requiere rechazo a lo femenino; además, el anhelo por el padre se confunde con el homoerotismo. Como resultado, el macho rechaza vehementemente todo lo femenino incluyendo y especialmente la atracción a un macho, esto es, al padre. Stephen Ducat también involucra a los padres ausentes en la creación de lo que él denomina "femifobia", en la medida que frecuentemente el padre ausente intensifica la identificación del niño infante con la madre emocionalmente y muchas veces físicamente (Ducat, 2004). Consecuentemente, cuando la separación comienza, es duro y resulta en una crónica envidia del útero. ${ }^{7}$

Esto nos acerca un paso más a entender el misterioso conflicto que forma el fundamento psicológico de la femifobia. La feminidad masculina es claramente un tabú en una cultura masculinamente dominante, en parte porque las mujeres y todo lo femenino son de un estatus más bajo. Pero para realmente entender el tabú contra el manifestar o el siquiera sentir alguna similitud con las mujeres, lo tenemos que reflejar sobre el hecho de que los tabúes existen sólo contra esas cosas que las personas quieren hacer. Por ejemplo, a diferencia del incesto, travestismo o exhibicionismo, no hay tabú contra el tener sexo con queso... Cuando llega a ser femifobia, como veremos, lo que energiza al tabú contra la feminidad masculina es que bien al fondo, fuera de lo conciente, tantos hombres lo quieren violar. (Ducat, 2004, 28-29)

Julia Serrano también discute sobre este fenómeno, aunque ella lo etiqueta como effemimania: "una obsesión con la "feminidad masculina"” (Serano, 2007, 129). Esta obsesión incluye los asuntos que Ducat levanta, pero es también usado para explicar por qué el travestismo de hombre a mujer es considerado un asunto psiquiátrico, mientras que de mujer a hombre no. La idea dominante de que lo masculino es mejor que lo femenino significa que el huir de lo femenino no es patológico, pero el adoptarlo, para machos, ciertamente lo es. Cressida Heyes concurre en esto cuando escribe: "Para expresar masculinidad... es común el despreciar lo femenino, tal como expresar lo femenino es a 
menudo el implicarse a uno mismo en su propia opresión" (Hayes, 2003, 1112).

El bigenerismo, al codificar la distinción entre macho y hembra, hombre y mujer, masculino y femenino, crea cultura virulentamente sexista, heterosexista y transfóbica sólo por la valoración de los sexos. Tal valoración crea una situación en donde la identificación errónea de la categoría sexual basada en la manifestación del género no deja espacio para la tolerancia. Hopkins ofrece tres explicaciones posibles para la homofobia, y luego concluye: "Residen en un campo de diferenciación desigual, binaria, sexual y de género. Detrás de toda homofobia, independiente de su desarrollo, expresión, o motivación, está el fondo del heterosexismo. Detrás de todo heterosexismo está el fondo de identidades generizadas" (Hopkins, 1998, 179).

En la próxima parte de este ensayo primero defino bigenerismo, y luego presento tres modelos que divergen de él en distintos grados. El modelo final, el no-generismo, es uno en donde simplemente no hay aparato conceptual que nos permita definir e identificar género o sexo. Es un modelo en extremo radical y que suprime, mantengo, al anfitrión de aparatajes sociales perniciosas que dañan a una multitud de personas $\mathrm{y}$, especialmente, a mujeres. El no-generismo podría, sin embargo, no ser inatractivo para aquellos que adoptan, disfrutan, o por distintos motivos ven la necesidad de una bifurcación de género. El bigenerismo tiene adherentes entre algunos teóricos que mantienen que hay características centrales, esenciales e inmutables, sostenidas por un subconjunto de humanos que los demarcan como pertenecientes a un sexo en particular. Además, algunos transexuales no estarían inclinados a aceptar ningún análisis del fenómeno sexo/género, el cual que no les permitió volverse miembros del sexo con el que se identifican, mientras otros aún podrían sostener una versión más débil del bigenerismo, pero aún adherir a la noción central de dos géneros fundacionales. De este modo varias teóricas feministas argumentan que la delineación de una clase identificable de personas conocidas como "mujeres" es, al menos, politicamente relevante" (Stefano, 1991 y Friedman, 1996 son dos ejemplos). Además, algunos hombres trans y mujeres trans insisten en mantener afiliación a su comunidad escogida, tal como existe ahora.

Problemas bien conocidos existen en los sistemas que buscan mantener un marco generista. Primero están las dificultades notorias en definir justamente quien está y no está en la clase mujer. Hale, por una parte, ha señalado que cada definición especifi- 
cativa choca con contraejemplos que no pueden ser fácilmente descartados, y debemos finalmente conformarnos con una semejanza de familia Wittgensteiniana (Hale, 1996). La historia de los intentos Olímpicos de determinar quien pertenece o no a la clase avala la dificultad de formar una definición tan directa. Además, el aplicar tales definiciones con frecuencia nos lleva a asuntos políticos complejos en donde las intervenciones filosóficas tienen poco efecto. Ejemplos de esto incluyen tales actividades divisivas como la exclusión de personas trans del Festival de Música de Mujeres de Michigan o el empleo en refugios de mujeres.

Ciertamente, en el mundo generista de hoy la definición puede ser muy importante, y, como lo señala Elliot, la discusión levanta cuestiones cruciales (Elliot, 2004). Sin embargo, aunque la cuestión de quién es y no es una mujer es importante y puede impactar a personas trans en distintas formas (ver Gilbert, 2001), el modelo que estoy presentando elude ese asunto. El esquivo es por dos razones. La primera es que en un modelo no-generista la cuestión se vuelve dudosa en la medida que los escenarios a los que se refiere ya no existen. Pero la segunda razón es la inhabilidad de estar seguros de cómo sería un mundo no-bigenérico. Estamos tan lejos de provocar tal revolución social que la preocupación sobre la eliminación de la dicotomía mujer/hombre en este punto, para ponerlo en términos medianos, es abstracta. Seguramente pasarán generaciones antes de que algún modelo no-generista fuerte pueda suceder. En efecto, no podemos anticipar realmente las consecuencias políticas y sociales hasta que estén mucho más cerca, ni tampoco podemos siquiera imaginar cómo se podría sentir el perder un sistema que está tan completamente integrada a nuestras psiquis. Entonces prefiero eludir la cuestión y en su lugar encomendarme a presentar los modelos.

El Bigenerismo Estricto se puede definir como a continuación:

I. Sostiene: a) una distinción de género binaria; b) una valorización mayor para lo macho (sexualmente masculino) y lo masculino; y c) una estricta correlación entre sexo y género.

A un pequeño paso de un modelo de bigenerismo estricto, y uno que no elimina el sexismo, estaría una cultura donde hombres femeninos son aceptados como objetos sexuales por otros hombres. Esto quiere decir, en términos de objetos sexua- 
les, que hombres femeninos estarían incluidos con las mujeres. En ese caso, los varones femeninos podrían evitar ciertos tipos de oprobios, pero sólo hasta el mismo punto en que el patriarcado también protege a mujeres. La distinción no es entre macho y hembra, sino entre objeto sexual y no-sexual con su concomitante vulnerabilidad a la violencia y violación. Entonces obviamente no es una gran ventaja porque sigue involucrando la relación de dominación sobre el cual descansa el sexismo, tanto como la intolerancia y la ambigüedad genérica. Aún así, es un cambio, y desde el punto de vista de las personas trans que "pasan", no es uno inconsecuente. ${ }^{8}$ Puede ser descrito de la siguiente manera:

II. El Bigenerismo Blando sostiene: a) una distinción de género binaria; y b) una mayor valorización para lo macho (sexualmente masculino) y lo masculino.

En II aún hay sólo hombres y mujeres y uno está en una categoría y el otro en otra, pero hay una desgenitalización parcial para el enlace sexo/género. La ventaja, tal como es, es que emblandece tales cuestiones como aquellas levantadas por Talia Bettcher con respecto a la decepción y el tratar a las personas trans como malignos impostores (Bettcher, 2007). El Bigenerismo Blando supone la desgenitalización del género, para que sexo y género no sean estrictamente isomórficos. Pero es sólo el isomorfismo lo que crea dificultades para personas ambas trans y no-trans cuya apariencia de género no combina por completo con su sexo. “La presentación del género es comúnmente considerada como un signo del cuerpo sexuado, que significa cuerpo sexuado, que comunica cuerpo sexuado. Y es por esta razón precisamente que las personas trans que "desalinean" la presentación del género y el cuerpo sexuado son interpretados como impostores o pretendientes" (Bettcher, 2007, 52). Las implicancias de esto para las personas trans son duras si nada menos que el Bigenerismo Blando existe, como es ahora el caso. Bettcher continúa:

Pues si por lo que he reclamado es correcto entonces impostor / pretendiente no es meramente uno de los muchos estereotipos desafortunados que plagan a las personas trans. Más bien, fluye primariamente de una relación comunicativa fundamental que obtiene entre presentación y cuerpo -una relación dentro del cual incluso personas no-trans están implicadas. Si presentación de género significa cuerpo sexuado, nos involucramos en una "falsa representación"... y dado que la única "opción" 
es entre la decepción invisible y la pretensión visible, aparecería que este sistema representacional en realidad previene a las personas trans de existir en absoluto (excepto, por supuesto, como falsos y farsantes).(55)

El Bigenerismo Blando es apenas el Santo Grial, y Bettcher no aboga por frenar ahí. Poco hace en cuanto a eliminar el sexismo, la violencia hacia mujeres, o la sistémica discriminación hacia mujeres y minorías sexuales o de género. Mientras que ofrece cierta comodidad a aquellos que "pasan" de un género a otro, poco ayuda a aquellos que no "pasan" de un género a otro, o que demuestran un género mezclado. Como señala Namaste, "Las mujeres y los hombres que transgreden los límites aceptables de la auto-representación, entonces, están entre aquellos bajo el mayor riesgo de asalto. Los asaltos a los hombres juzgados de ser "afeminados" o a mujeres consideradas "masculinas" revelan las maneras en que el género y la sexualidad están entrelazados" (Namaste, 2000, 141)

Ir más allá del bigenerismo blando es en realidad abandonar el modelo binario; ¿pero qué significa exactamente el abandonar el bigenerismo? La respuesta no es del todo clara. ¿Conlleva el acabar con las categorías de mujer y hombre, para que un individuo sea una persona sin una categoría? ¿O simplemente es hacer las categorías independientes del sexo? ¿Qué pasa con lo femenino y lo masculino? Seguramente una manera de derrotar el bigenerismo es hacer que lo masculino y lo femenino sean independientes de mujer y hombre o, quizás mejor aún, independientes de hembra y macho. Esto requiere de un sistema diferente.

El tercer tipo de organización de género involucra una desgenitalización del género y una mayor separación de la presentación de género en tanto suponiendo el sexo. En este modelo, llámenlo generismo No-binario, uno ve las características como generizadas más que a los individuos. Entonces, por ejemplo, "lanzar como una niña" no significa que uno es una niña o que tiene un cierto tipo de genitales, o, importantemente, el hacer una cosa en, digamos, una manera masculina no supone que uno hace otras cosas en una manera masculina. Claro, uno bien podría tener un nexo con características de género consideradas femeninas o masculinas, e identificarse felizmente con eso. Sin embargo, este permite la selección o posesión de características ya de la columna femenina o masculina. La definición es: 
III. Generismo no-binario no supone una distinción binaria pero mantiene que las características masculinas son valoradas por sobre las femeninas.

El Modelo III es, en su corazón, un acercamiento multifactorial tal como el descrito por Janet Spence. Ella aboga por la separación del sentido de feminidad y de masculinidad de un individuo de lo que es interpretado como femenino y masculino. Ella escribe,

Aún entre aquellos con identidad de género fuerte y no ambigua, hombres y mujeres no exhiben todos los atributos, intereses, actitudes, roles, y comportamientos esperados por su sexo de acuerdo a los estereotipos descriptivos y prescriptivos de su sociedad sino sólo algunos de ellos. También podrían manifestar algunas de las características y comportamientos asociados al otro sexo. (Spence, 1993, 633; ver también Spence, 1985)

Entonces en el Modelo II, generismo no-binario, femenino y masculino son independientes de hembra (sexo femenino) y macho (sexo masculino), y en su lugar se refieren a colectividades de propiedades. De esto se sigue que las marimachos y mariquitas no serían acosados simplemente por violar reglas del género, porque las características de comportamiento no están genitalmente vinculados. Más bien, son las características que tienen una valoración, y no la persona que lleva la característica. No existe tal cosa como un marimacho porque el tener características masculinas actualmente atribuidas a esa categoría no tendría una implicación genital como el sexo. Mutatis mutandis para afeminados, quienes, como los marimachos simplemente dejarían de existir. Sin embargo, el modelo sigue siendo patriarcal ya que permanece una preferencia social por la masculinidad, y a las personas masculinas les irá mejor. Pero un macho que no es masculino, o una hembra que no es femenina no sufrirá sobre esas bases. Entonces, el generismo no-binario es un mejoramiento sobre el bigenerismo, pero aún le falta largo camino por recorrer para alcanzar mi meta propuesta de crear una sociedad que no use el sexo o el género como medio para distribuir generosidad social.

El paso final para alejarse del bigenerismo es la eliminación de la valoración del género en su totalidad. En otras palabras, en este modelo, los mismos términos femenino y masculino no se 
refieren a colectividades de propiedades, y, consecuentemente, ninguna propiedad es valorada más o menos que cualquier otra. Ahora mismo tenemos algún sentido, aunque un sentido incierto, de lo que se quiere decir por femenino y masculino. En los tres modelos anteriores, aún hay un conjunto de predicados que se aplican colectivamente a los términos femenino y masculino, pero en el IV, un sistema completamente no-bigenerista, no existen tales colectividades conceptuales. (I reproduce III por conveniencia).

III. Generismo no-binario no supone una distinción binaria, pero mantiene que características masculinas sean valoradas por sobre las femeninas.

IV. No-generismo no supone distinción binaria ni valoración social haciendo que lo masculino sea más valorado que lo femenino.

Con el no-generismo simplemente no hay nada que sea, digamos, femenino: no hay una manera de hablar, caminar, vestir, pensar o comunicar. Estas formas, claro, todavía existen, por ejemplo una persona puede ser cuidadosa o agresiva, pero no hay mayor asociación de ellos con una categoría de género. Esto va más allá de la idea levantada por Chodorow: "Cada persona personalmente se declina y crea su "propio" género, y hay varias masculinidades y feminidades individuales" (Chodorow, 1995, 521). El no-generismo alcanza este ideal y va más allá porque hablar sobre masculinidad y feminidad simplemente no tiene sentido.

Es el no-generismo el que se acerca al ideal de eliminar el sexismo, heterosexismo, homofobia, transfobia y discriminación sexual. La existencia de todos estos fenómenos de categorización social depende de la manifestación del género de acuerdo con las reglas del bigenerismo. Ridgeway y Correll lo ponen de esta manera: "Creencias sobre género ampliamente creídas son efectivamente reglas culturales o instrucciones para representar la estructura social de diferencia e inequidad que entendemos por género" $(2004,511)$. Mientras ellos están enfatizando la discriminación en contra de las mujeres, lo mismo se aplica a la discriminación en contra de gays, lesbianas, los intersexuados y los transexuados. Sin género uno es atraído o le gusta una persona, no a un portador de cierto tipo de genitales. Uno podría estar atraído a gente suave y vulnerable, pero no habría conexión necesaria 
entre esas propiedades y cualquier supuesto sobre el sexo. En lugar de identificar primero el sexo, y luego determinar la atracción, lo opuesto podría ser verdad. ${ }^{9}$

¿Cómo, entonces, sería tal mundo? ¿Es posible? ¿Podemos concebir un mundo sin género? Barbara Risman escribe,

No hay motivo, excepto el vértigo de transición que acompañará al proceso de desmantelarlo, que una visión utópica de un mundo justo involucre cualquier estructura de género en absoluto. ¿Por qué deberíamos necesitar elaborar en la distinción biológica entre los sexos? Debemos acomodar diferencias reproductivas para el proceso de reemplazo biológico, pero no hay razón a priori para que debamos aceptar cualquier otra diferenciación de roles simplemente basada en una categoría sexual biológica. (Risman, 2004, 446)

Sandra Bem desea un mundo similar: "Me quiero mover más allá del androcentrismo y polarización del género para abogar por una visión de utopía en donde la polarización del género, al igual que el androcentrismo, hayan sido tan completamente desmantelados que -excepto los contextos casi biológicos como la reproducción- la distinción entre macho y hembra ya no organice la cultura ni la psique" (Bem, 1993, 192; ver también Bem, 1995). Si llegamos a tal mundo, estaríamos eliminando las jerarquías multitudinarias sobre lo que gran parte de la sociedad, nuestra y de otros, es construida. Si no hubieran categorías de mujer y hombre, no habrían transexuales y travestis, no habría homosexualidad. El preferir parejas sexuales que tienen vaginas en lugar de penes no significaría más que preferir a una persona más alta que uno o a alguien de nariz pequeña. En un mundo desgenitalizado, la categoría sexual ya no existe. Las implicancias, cuando uno comienza a entrar en el fantástico mundo del no-género, son intrigantes y alucinantes, pero no serán perseguidas aquí. En verdad, me puedo imaginar varios escenarios y varios mundos en donde el género no es central o no existe, y la mayoría son espléndidos. Incluso la preocupación de Risman de que "Nadie quiere ser parte de una revolución en donde ella o él no pueden "bailar sucio" (dirty dance) (Risman, 2004, 446) no es atemorizante. Como un travesti comprometido (Gilbert, 2000) yo he "bailado suciamente" con ambos sexos, ambos géneros, $\mathrm{y}$ algunas veces con parejas cuyo estatus genital es un completo misterio para mi, y, francamente, no de mi incumbencia. Pero el baile ha sido grandioso.

Arriba he usado el género como un concepto masivamen- 
te poderoso, definitorio, y de gran alcance. Algunos pueden pensar que esto es demasiado, pero estoy respetuosamente en desacuerdo. El género puede no justificar todo lo malo en el mundo como, por ejemplo, Ducat lo puede estar implicando, pero de todas maneras tiene bastante para qué responder. La segregación del mundo en dos sexos es, sistemática y diariamente, una función del género y su categoría sexual correlativa; y es este hecho lo que le da existencia al sexismo, heterosexismo, homofobia y transfobia. La salvación descansa sobre la combinación de la desgenitalización del género y la descategorización de predicados personales. Esto no sucederá pronto ni fácilmente; un mundo no-generista no está a la vuelta de la esquina. Mientras tanto, cualquier cosa que puede ser hecha para reducir la tiranía del bigenerismo es un paso adelante. Cualquier cosa que ayude en derrotar el bigenerismo es progresivo y liberador. Esas actividades y credos que trabajan para ese fin incluyen el feminismo, transgenerismo, homosexualidad y heterosexualidad carente de heterosexismo, todos los cuales violan las reglas del género.

Comencé hablando sobre la conexión entre el bigenerismo, sexismo, y el heterosexismo, pero espero que haya quedado claro que, en muchas maneras, el primero es un componente y consecuencia de los últimos dos. La libertad que es requerida es la libertad de ser una persona, una simple, desgenerizada, e individualizada persona.

\section{Notas}

Me gustaría agradecer las referencias anónimas de Hypatia y a los editores del número especial, Talia Bettcher y Ann Garry, por sus amables e intuitivos comentarios. También quisiera agradecer a Diane Gilbert y a los estudiantes de PHIL 6290, mi curso de postgrado durante el periodo de invierno de 2007-08, Asuntos recientes sobre Teoría Trans/ de Género (Recent Issues in Trans/Gender Theory). Este trabajo ha sido apoyado por un Canada Social Sciences and Humanities Research Council Standard Grant \# 410- 2008-1999.

1 Christine Overall (2007) tiene una interesante discusión sobre la segregación del baño relacionado a espacios públicos y el sexismo consiguiente que esto conlleva.

2 En una reciente y horrible clase, un quinceañero estudiante de secundaria , Larry King, fue asesinado por otro estudiante. Según el abogado: "Si no vieron la ejecución acercarse, varios de los pares de King en el colegio sabían que estaba siendo acosa- 
do por ser orgullosamente gay y desobedeciendo convenciones masculinas al decorar su uniforme escolar con sombra de ojos y botas de taco alto" (Broverman 2008). También, ver Halberstam nuevamente sobre baños (1998).

3 Más tarde en la vida se pueden "devolver las jugadas". Muchos niños dorados, especialmente aquellos provenientes de riqueza, continuarán siendo exitosos. Sin embargo, en la era tecnológica aquellas niñas y niños relegados al club de matemáticas con frecuencia se recuperan. En varios casos, sin embargo, el daño emocional y a su ego no se revierte.

4 Mientras algunos gobiernos requieren una cirugía de reasignación de sexo (SRS) para cambiar legalmente el sexo de uno, no es requerido para que uno viva en un género preferido. Es (apenas) concebible que un gobierno pueda requerir SRS para combinar elección de género, pero esto sería legalmente fascista, mientras que el bigenerismo en sí mismo es sólo culturalmente fascista.

5 Hay una cantidad considerable de trabajo hecho sobre este tema en la psicología social, especialmente con respecto a leer y malinterpretar señales de excitación sexual y atracción. Una obra temprana e importante es Birdwhistell (1970); más recientemente Morrison y otros (2007) proveen un ejemplo interesante de trabajo en curso.

6 Ver, por ejemplo, Charlotte Furth:

Los cuerpos generizados son entendidos a través de repertorios culturalmente específicos de gestos y emociones que asignan significancia a los actos y definen objetos de deseo a nivel de lo erótico; al igual que por códigos de lo masculino y femenino a nivel de experiencia psíquica e identidad personal. Esta manera de pensar se ha intersectado con los análisis feministas de género como socialmente construidos a través de parentesco, religión, y otros roles, y el rechazo feminista de la "biología" como una base natural de distinciones de género. De acuerdo al sexo, referido a las características físicas y capacidades biológicas, es distinguido del género, el cual representa el significado cultural y social adjuntado a los cuerpos sexuados. Lo "sexual" se vuelve aquel aspecto del género que trata con significados eróticos y biológicos culturalmente construidos. (Furth, 1993, 479-80)

7 Esto hace surgir la intrigante idea de que las irónicas reflexiones de Steinem sobre la envidia del útero quizás no sean tan irónicas (Steinem, 1994).

8 Vale la pena notar que cuando tal clasificación no es voluntaria, entonces lo socio-político de la situación cambia dramáticamente. En verdad vemos este fenómeno cuando las hembras no están sexualmente disponibles para los machos, pero otros, machos débiles, sí lo están; las cárceles son un ejemplo de esto. Cuando 
forzado, este modelo no está previsto para ser una recomendación de actividad.

9 Existen sugerencias acerca de que algunas interacciones bisexuales son como esto, hasta el punto que la atracción podría proceder independientemente de la categoría sexual, pero no cabe duda acerca de si la identidad de género aun existe.

\section{Bibliografía}

Bem, Sandra L. 1993. The lenses of gender: Transforming the debate on sexual inequality. New Haven: Yale University Press.

1995. Dismantling gender polarization and compulsory heterosexuality: Should we turn the volume down or up? Journal of Sex Research 32 (4): 329-35.

Bettcher, Talia Mae. 2007. Evil deceivers and make-believers: On transphobic violence and the politics of illusion. Hypatia 22 (3): 43-65.

Birdwhistell, Ray L. 1970. Masculinity and femininity as display. In Kinesics and context: Essays on body motion communication. Philadelphia: University of Pennsylvania Press, pp. 39-46.

Bornstein, Kate. 1994. Gender outlaw: On men, women, and the rest of us. New York: Vintage Books.

Broverman, Neal. 2008. Mixed messages. Advocate, no. 1005. Available at http:/ / www.advocate.com/print_article_ektid52689 (accessed March 12, 2008).

Butler, Judith. 1990. Gender trouble: Feminism and the subversion of identity. New York: Routledge.

1991. Imitation and gender substitution. In Inside/out: Lesbian theories, gay the- ories, ed. D. Fuss. London: Routledge, pp. 1331.

Chodorow, Nancy J. 1995. Gender as a personal and cultural construction. Signs 20 (1): 516-44.

Ducat, Stephen. 2004. The wimp factor: Gender gaps, holy wars, and the politics of anxious masculinity. Boston: Beacon Press.

Elliot, Patricia. 2004. Who gets to be a woman?: Feminist politics and the question of trans-inclusion. Atlantis 29 (1): 13-20.

Friedman, Marilyn. 1996. The unholy alliance of sex and gender. Metaphilosophy 27 (1-2): 78-91.

Furth, Charlotte. 1993. Androgynous males and deficient females: Biology and gender boundaries in 16th and 17th century China. In The lesbian and gay studies reader, ed. Henry Abelove, Michéle A. Barale, and David M. Halperin. New York: Routledge, pp. 479-97.

Garfinkel, Harold. 1967. Studies in ethnomethodology. Englewood Cliffs, N.J.: Prentice- Hall.

Gilbert, Michael A. 2000. The transgendered philosopher. International Journal of Transgenderism 3: Available at http:/ / www.sympo- 
sion.com/ijt (accessed January 5, 2008).

2001. A sometime woman: Gender choice and cross-socialization.

In Unseen genders: Beyond the binaries, ed. F. Haynes and T. McKenna. New York: Peter Lang, pp. 41-50.

Gilbert, Miqqi Alicia. 2003. Bigenderism. Transgender tapestry 102: 16-7.

Goffman, Erving. 1979. Gender Display. In Gender advertisements. New York: Harper \& Row, 1-9.

1977. The arrangement between the sexes. Theory and Society 4 (3): $301-31$.

Halberstam, Judith. 1998. Female masculinity. Durham, N.C.: Duke University Press.

Hale, C. Jacob. 1996. Are lesbians women? Worries about Monique Wittig. Hypatia 11 (2): 94-121.

Heyes, Cressida J. 2003. Feminist solidarity after queer theory: The case of transgender. Signs 28 (4): 1093-122.

Hopkins, Patrick. 1998. Gender treachery: Homophobia, masculinity, and threatened identities. In Race, class, gender, and sexuality: The big questions, ed. N. Zack, L. Shrage, and C. Sartwell. Oxford: Blackwell, pp. 168-86.

Kessler, Suzanne J., and Wendy McKenna. 1985. Gender: An ethnomethodological approach. Chicago: University of Chicago Press.

Kimmel, Michael. 1994. Masculinity as homophobia: Fear, shame, and violence in the construction of gender identity. In Theorizing masculinities, ed. H. Brod and M. Kaufman. Thousand Oaks, Calif.: Sage Publications, pp. 213-19.

Morrison, Edward R., Lisa Gralewski, Neill Campbell, and Ian S. Penton-Voaka. 2007. Facial movement varies by sex and is related to attractiveness. Evolution and Human Behavior 28:186-92.

Namaste, Viviane K. 2000. Genderbashing: Sexuality, gender, and the regulation of public space. In Invisible lives: The erasure of transsexual and transgendered people. Chicago: University of Chicago Press.

Overall, Christine. 2007. Public toilets: Sex segregation revisited. Ethics and the Envi- ronment 12 (2): 71-91.

Ridgeway, C.L., and S.J. Correll. 2004. Unpacking the gender system: A theoretical per- spective on gender beliefs and social relations. Gender and Society 18 (4): 510-31.

Risman, Barbara J. 2004. Gender as a social structure: Theory wrestling with activism. Gender and Society 18 (4): 429-50.

Serano, Julia. 2007. Whipping girl: A transsexual woman on sexism and the scapegoating of femininity. Emeryville, Calif.: Seal Press.

Spence, Janet T. 1985. Gender identity and its implications for the concepts of mascu- linity and femininity. Nebraska Symposium on Motivation 32:59-95.

1993. Gender-related traits and gender ideology—evidence for a 
multifactorial theory. Journal of personality and social psychology 64 (4): 624-35.

Stefano, Christine Di. 1991. Who the heck are we? Theoretical turns against gender. Frontiers: A Journal of Women Studies 12 (2): 86-108.

Steinem, Gloria. 1994. Womb envy, testyria, and breast castration anxiety. MS 4 (5): 49-56.

West, Candace, and Don H. Zimmerman. 1987. Doing Gender. Gender \& Society 1 (2): 125-51. 